\title{
Synergetic effects of carbon nanotube- graphene nanoplatelet hybrids in carbon fibre reinforced polymer composites
}

\author{
Magda Silva ${ }^{1}$, Diogo Vale ${ }^{1}$, Jéssica Rocha ${ }^{1}$, Nuno Rocha ${ }^{1}$, and Raquel Miriam Santos ${ }^{1, *}$ \\ ${ }^{1}$ Institute of Science and Innovation in Mechanical and Industrial Engineering - INEGI/LAETA, \\ Campus da FEUP, Rua Dr. Roberto Frias, 4200-465 Porto, Portugal
}

\begin{abstract}
Hybrid filler systems of carbon-based nanoparticles with different geometry shapes, one-dimensional (1D-) carbon nanotubes (CNTs) and two-dimensional (2D-) graphene nanoplatelets ( $\mathrm{GnPs}$ ), were dispersed into epoxy matrix, using an intensive mixer, to evaluate their promising synergistic effects. In this work, the influence of different $\mathrm{CNT} / \mathrm{GnP}$ ratios on the dispersion level, electrical and mechanical performance of epoxy-based nanocomposites was investigated. It was found that the size and number of $\mathrm{GnP}$ agglomerates are significantly reduced with the incorporation of CNTs, due to the formation of a cosupporting three-dimensional (3D-) architecture that delays reagglomeration of the nanoplatelets. The combination of CNTs and GnPs, at an overall concentration of 0.043 wt. \%, synergistically increase the mechanical performance and reduce the electrical percolation threshold of nanocomposites comparatively to the single filled systems. The transversal tensile properties, including elastic modulus $-\mathrm{E}_{2}$ and failure strength $-\mathrm{Y}_{\mathrm{t}}$, of carbon fibre reinforced polymer (CFRP) composites were studied and synergetic effects were also found when combining CNTs with GnPs.
\end{abstract}

\section{Introduction}

Carbon-based nanostructured materials, such as diamond, carbon nanotubes (CNTs), fullerenes $\left(\mathrm{C}_{60}\right)$, graphite and its derivatives, have caught the attention of industrial and scientific communities owing to their potential for developing high-performance and smart materials and, in particular, enhancing carbon fibre reinforced polymer (CFRP) composites $^{[1-3]}$.

Graphene nanoplatelets (GnPs), a two-dimensional (2D-) hexagonal structure of $s p^{2}$ hybridized carbon atoms with open edges, obtained by intercalation and exfoliation of graphite, is a promising low-cost alternative to carbon nanotubes $(\mathrm{CNTs})^{[4-5]}$. Graphite is a commonly used naturally occurring flake material, known as the most thermodynamically stable and softest form of carbon, with high stiffness $(1 \mathrm{TPa})$, good electrical $\left(>10^{3} \mathrm{~S} \cdot \mathrm{m}^{-1}\right)$ and in-plane thermal $\left(2000 \mathrm{~W} \cdot \mathrm{m}^{-1} \cdot \mathrm{K}^{-1}\right)$ conductivities ${ }^{[6]}$, as well as unconventional magnetic and flame retardant features ${ }^{[7]}$. Its unique graphitized planar structure, provided

\footnotetext{
*rmsantos@inegi.up.pt
} 
by a $2 \mathrm{D}$ - path for phonon transport and an ultrahigh aspect ratio, allows a large surface contact area with the polymeric molecules, promoting a thermal conductivity enhancement of the final composite ${ }^{[8-11]}$.

An overview of the literature on epoxy-based nanocomposites reveals that lower percolation thresholds are typically achieved through the addition of CNTs in comparison with $\mathrm{GnPs}^{[12]}$. Therefore, the use of hybrid filler systems based on the synergetic effects between carbon nanofillers having different geometry shapes, including 1D-CNTs and 2DGnPs, has been reported as a promising strategy for developing multifunctional CFRP composites with enhanced electrical and thermal conductivity ${ }^{[13-14]}$. Yue et al. ${ }^{[15]}$ showed that the combination of CNTs and GNPs in a ratio 8:2 enhances the flexural properties and the electrical conductivity compared to the single filled systems. This behaviour is associated with the easier formation of an interconnected network promoted by a better dispersion state of GnPs in the presence of CNTs.

When used in polymer-based CFRP composites, the unusual intrinsic properties of carbon-based nanostructures are severely restricted by both optimum dispersion state and interfacial bonding with the polymeric matrix. The dispersion of CNTs and GnPs is challenging owing to their strong tendency to self-aggregate promoted by van der Waals cohesive forces and large surface areas, or additional $\pi$-stacking between separately graphene sheets in the case of GnPs. Their chemical inertia also precludes the formation of strong interfaces with most of common polymers, restricting the load transfer ability from the matrix to the carbon nanotubes-graphene nanoplatelets ${ }^{[9,16]}$. These parameters strongly influence the agglomerate cohesive strength (directly proportional to packing density and inversely proportional to particle surface area), and have been correlated with the mechanisms and kinetics of dispersion ${ }^{[17]}$.

In this study, a strategy was designed to improve the performance of CFRP composites by incorporating hybrid systems (1D-CNTs and 2D-GnPs). Therefore, modified epoxybased suspensions containing different loadings of MWCNTs, GnPs or combinations of them were prepared using a three-roll mill, under optimized mixing conditions, to ensure a good and stable dispersion. This intensive mixer attempts to create high hydrodynamic shear stresses developed during flow, it is a similar approach to industrial practices, and is less environmentally aggressive (does not require the use of solvents) ${ }^{[18]}$. Afterwards, epoxy-based suspensions were reinforced with dry carbon fibres by a lab-scale drumwinder and the obtained pre-impregnated unidirectional (UD) sheets were converted into composite laminates. The influence of hybrid systems on the transversal properties of CFRP composites was investigated and correlated with the different formulations.

\section{Experimental}

\subsection{Raw Materials}

Araldite LY $556^{\circledR}$ (Huntsman Corporation, Germany) with a viscosity of $10-12 \times 10^{3}$ $\mathrm{mPa} \cdot \mathrm{s}$ and density of $1.15-1.20 \mathrm{~g} \cdot \mathrm{cm}^{-3}$ was used as a pre-polymer matrix, widely applied in aerospace industry. A pre-mixture of aradur $1571^{\circledR}$ and accelerator $1573^{\circledR}(23: 5: 100$ per polymer) the hardener XB $3403^{\circledR}\left(28: 12: 100\right.$ per polymer) were further added to LY $556^{\circledR}$ resin and kept under mechanical stirring for 15 minutes.

The thin multi-walled carbon nanotubes (MWCNTs) $\mathrm{NC} 7000^{\circledR}$ was supplied by Nanocyl, Belgium (average diameter of $9.5 \mathrm{~nm}$, average length of $1.5 \mu \mathrm{m}$, average surface area of $250-300 \mathrm{~m}^{2} \cdot \mathrm{g}^{-1}$ and purity $>90 \%$ ). The graphene nanoplatelets $\mathrm{xGnP}^{\circledR}$ Grade-M, denoted here as GnP, was purchased by XG Sciences, Inc., Lansing, U.S.A. (average 
thickness of $\sim 6-8 \mathrm{~nm}$, average particle diameter of $15 \mu \mathrm{m}$ and average surface area from 120 to $\left.150 \mathrm{~m}^{2} \cdot \mathrm{g}^{-1}\right)$.

Tenax $^{\circledR}$ E HTA40 E13 (Toho Tenax, Germany) with 6K tow size and a density of 1.77 $\mathrm{g} \cdot \mathrm{cm}^{-3}$ was used as continuous carbon fibres. CFs present a tensile strength of $4228.4 \mathrm{MPa}$, a tensile modulus of $238.7 \mathrm{GPa}$ and an elongation break of $1.66 \%$.

\subsection{Nanocomposites preparation and characterization}

Modified epoxy-based suspensions containing different loadings and types of carbon nanoparticles were prepared using a three-roll mill EXAKT $80^{\circledR}$ from EXAKT Technologies, Inc., at $200 \mathrm{rpm}$. This intensive mixer contains three rolls - the feed $\left(\omega_{1}\right)$, the centre $\left(\omega_{2}\right)$ and the apron $\left(\omega_{3}\right)$ roll - where the centre and the apron roll rotate three $\left(\omega_{2}=3\right.$ $\left.\omega_{1}\right)$ and nine $\left(\omega_{3}=9 \omega_{1}\right)$ times faster than the feed roll, respectively. Different gaps $\left(\delta_{1}=\right.$ $120 \mu \mathrm{m}$ and $\delta_{2}=40 \mu \mathrm{m}, \delta_{1}=90 \mu \mathrm{m}$ and $\delta_{2}=30 \mu \mathrm{m}, \delta_{1}=60 \mu \mathrm{m}$ and $\delta_{2}=20 \mu \mathrm{m}, \delta_{1}=30$ $\mu \mathrm{m}$ and $\delta_{2}=10 \mu \mathrm{m}$, and $\delta_{1}=15 \mu \mathrm{m}$ and $\delta_{2}=5 \mu \mathrm{m}$ ) were applied to the mixture aiming to create strong hydrodynamic shear stresses. Afterwards, curing agents were added to the suspension, poured into silicone moulds and cured at $120^{\circ} \mathrm{C}$ for 2 hours.

The dispersion state of nanofillers was evaluated by light optical microscopy (LOM) in transmission mode, using a $\mathrm{BH} 2$ Olympus microscope coupled to a digital camera Leica DFC 280 , with a $1.6 \mathrm{x}$ ocular and 20 or $40 \mathrm{x}$ objective magnification (total area of analysis of $3.5 \times 10^{5}$ or $8.6 \times 10^{4} \mu \mathrm{m}^{2}$, respectively). For this, $5 \mu \mathrm{m}$ thin sections were cut from nanocomposites at room temperature using a Leitz 1401 microtome with a glass knife at an angle of $45^{\circ}$. For each composition, 20 micrographs were analysed using Image ${ }^{\circledR}$ software to get information about: 1$)$ the area ratio $\left(\mathrm{A}_{\mathrm{r}}, \%\right)$, which is defined as the ratio between the sum of all agglomerates observed and total composite area of analysis, and 2) number of agglomerates per unit area $\left(N, \mathrm{~mm}^{-2}\right)$.

The DC electrical conductivity of the nanocomposites was measured with an automated Keithley 487 picoammeter/voltage source, with an applied voltage ranging between -10 and $10 \mathrm{~V}$. For this purpose, $\mathrm{Au} / \mathrm{Pd}$ electrodes were previously deposited on the surface of the sample by magnetron sputtering (Polaron SC502 sputter coater).

Tensile properties were obtained using an INSTRON 4208 universal instrument with a dog-bone shaped specimens, according to ISO 527-2. The experiments were performed using a load cell of $5 \mathrm{kN}$ and a constant crosshead speed of $1 \mathrm{~mm} \cdot \mathrm{min}^{-1}$.

\subsection{Pre-impregnated materials manufacturing and characterization}

Unidirectional pre-impregnated materials were prepared using a laboratory drumwinder under optimal conditions. Prepreg materials were further converted into CFRP composites with 16 plies ( $\sim 2 \mathrm{~mm}$ thickness) for the determination of the transversal tensile properties, according to ASTM D3039/D3039 M-17. The CFRP laminates were cured in an autoclave at $120{ }^{\circ} \mathrm{C}$ for 2 hours and 3.5 bar. The mechanical performance of CFRP composites were evaluated using an INSTRON 4208 universal instrument, at a crosshead speed of 2 $\mathrm{mm} \cdot \mathrm{min}^{-1}$ and a load cell of $100 \mathrm{kN}$.

\section{Results and Discussion}

The morphology of epoxy-based nanocomposites containing CNTs, GnPs and combinations of both, at an overall concentration of $0.71 \mathrm{wt} . \%$, was investigated by LOM, as shown in Figure 1. 


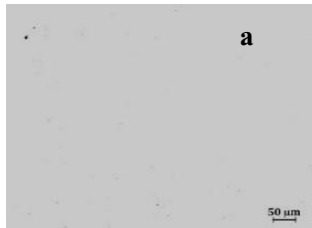

0.71 wt. \% CNTs

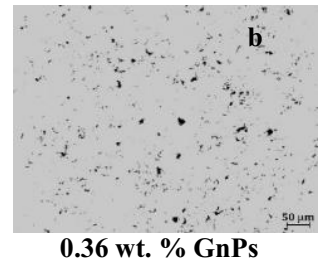

0.36 wt. \% GnPs

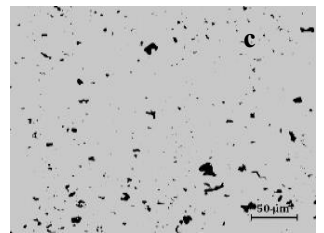

0.71 wt. \% CNTs/GnP, 50:50

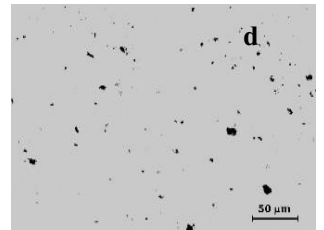

0.71 wt. $\%$ CNTs/GnP, 75:25

Fig. 1. Optical micrographs of the epoxy-based nanocomposites mixtures containing MWCNTs, GnPs or combination of both (MWCNTs/GnPs at an overall concentration of $0.71 \mathrm{wt} \%$ ).

The modified epoxy-based nanocomposite with 0.71 wt. \% of MWCNTs contains few small undispersed MWCNT agglomerates $\left(37\right.$ per $\left.\mathrm{mm}^{2}\right)$ in the $\mu \mathrm{m}$-size. According to the area ratio, only $0.048 \%$ of the agglomerates were in the measurement range above $5 \mu \mathrm{m}^{2}$. These results point out that the hydrodynamic shear stresses developed using a three-roll mill are strong enough to rupture the agglomerates into successfully smaller aggregates or to erode MWCNTs from the agglomerate surface.

The morphology of nanocomposites containing GnPs [Figure 1 b)] reveals lower levels of dispersion as detailed in Table 1. This result shows that CNTs are easier to be dispersed than GnPs, probably because stronger van der Walls interactions from the plane-to-plane contact of adjacent GnPs are additionally present ${ }^{[19]}$.

However, the dispersion state of GnPs can be significantly improved with the addition of CNTs due to their space hindrance effects and the tendency of CNTs to align on the surface of GnPs, leading to the formation of a co-supporting 3D architecture and minimizing the secondary aggregation of the platelets ${ }^{[15,20]}$. This is confirmed by the drop of the area ratio and number of agglomerates per unit area in 29 and $9 \%$, respectively, in a ratio of 50:50, comparing with the dispersion state of $0.36 \mathrm{wt} . \%$ of GnPs.

Table 1. Dispersion characterization of epoxy-based nanocomposites at an overall concentration of 0.71 wt. $\%$.

\begin{tabular}{|c|c|c|}
\hline Formulation & Area ratio, $\%$ & $\boldsymbol{N}, \mathbf{~ m m}^{\mathbf{2}}$ \\
\hline 0.71 wt. \% CNTs & $0.048 \pm 0.010$ & $37 \pm 14$ \\
\hline 0.36 wt. \% GnPs & $3.37 \pm 0.11$ & $3386 \pm 309$ \\
\hline 0.71 wt. \% CNTs/GnPs, 50:50 & $2.39 \pm 0.40$ & $3066 \pm 416$ \\
\hline 0.71 wt. \% CNTs/GnPs, 75:25 & $1.80 \pm 0.33$ & $2154 \pm 468$ \\
\hline
\end{tabular}

The electrical conductivity of epoxy-based nanocomposites containing different loadings of CNTs, GnPs and combinations of both is presented in Figure 2.

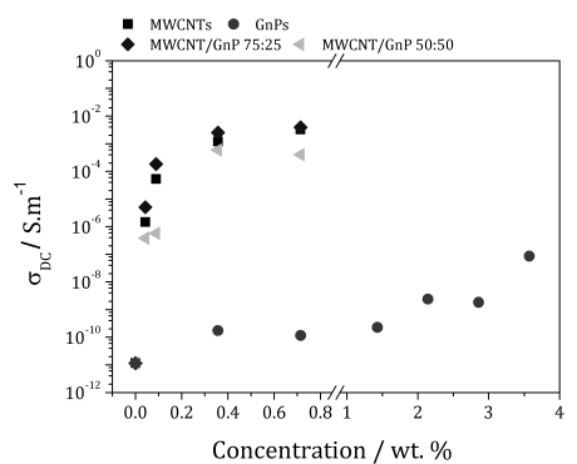

Fig. 2. Electrical conductivity of epoxy-based nanocomposites containing different loadings of CNTs, GnPs and combinations of both. 
The epoxy resin is an insulating material, exhibiting an electrical conductivity of $\sim 1.2 \times$ $10^{-11} \mathrm{~S} \cdot \mathrm{m}^{-1}$. After addition of only $0.043 \mathrm{wt}$. \% of MWCNTs, the DC electrical conductivity increases 6 orders of magnitude (from $10^{-11}$ to $10^{-5} \mathrm{~S} \cdot \mathrm{m}^{-1}$ ). At higher CNT loadings, a constant plateau is reached with a maximum value of $0.002 \mathrm{~S} \cdot \mathrm{m}^{-1}$, corresponding to a conductive material in the range of electromagnetic interference (EMI) shielding. This low percolation threshold indicates that the large aspect ratio of CNTs was maintained and a good dispersion was attained during mixing, allowing the formation of electrical pathways within the polymeric matrix ${ }^{[21]}$.

Nanocomposites containing GnPs exhibited lower electrical performance (from $10^{-11}$ to $\left.10^{-8} \mathrm{~S} . \mathrm{m}^{-1}\right)$ comparing to CNTs, even at high loadings. Synergetic effects were found when GnPs are combined with CNTs, the conductive network is formed at a lower concentration than for the single filled systems, attributed to the formation of a hybrid 3D-architecture that facilitates the electron transport throughout the polymer ${ }^{[10,15,22]}$.

Table 2. Mechanical properties of epoxy-based nanocomposites containing MWCNTs, GnPs, and combinations of both (MWCNTs:GnPs).

\begin{tabular}{|c|c|c|c|c|}
\hline Formulation & $\boldsymbol{E}, \mathbf{M P a}$ & $\begin{array}{c}\text { I.F.* } \\
\text { \% }\end{array}$ & $\boldsymbol{\sigma}$, MPa & $\begin{array}{c}\text { I.F.* } \\
\text { \% }\end{array}$ \\
\hline Epoxy & $2885 \pm 205.99$ & - & $47 \pm 5.32$ & - \\
\hline $\begin{array}{c}\text { 0.043 wt. \% } \\
\text { CNTs }\end{array}$ & $3338.08 \pm 474.77$ & +16 & $64.3 \pm 5.71$ & +37 \\
\hline 0.357 wt. \% GnPs & $2991.32 \pm 60.83$ & +3.7 & $50.63 \pm 3.07$ & +7.7 \\
\hline 1.429 wt. \% GnPs & $3156.58 \pm 105.61$ & +9.4 & $41.84 \pm 1.01$ & -11 \\
\hline $\begin{array}{c}0.043 \text { wt. \% } \\
\text { CNTs/GnPs, 50:50 }\end{array}$ & $3816.5 \pm 92.34$ & +32 & $47.41 \pm 7.27$ & +0.87 \\
\hline $\begin{array}{c}0.043 \text { wt. \% } \\
\text { CNTs/GnPs, 75:25 }\end{array}$ & $3875.58 \pm 143.58$ & +34 & $64.98 \pm 3.19$ & +38 \\
\hline
\end{tabular}

*I.F. - Improvement Factor

Modified nanocomposites with CNTs performed the best results in terms of quasi-static measurements (table 2). The incorporation of only 0.043 wt. \% of CNTs promotes a significant increase of the tensile modulus $\left(\sigma^{\prime}, 16 \%\right)$ and ultimate tensile strength $(E, 37$ $\%)$, showing their ability to reinforce polymers with high load transfer efficiency. Contrarily, only slight improvements were found for the $\sigma^{\prime}$ and $E$ with greater amounts of GnPs. This is probably due to the presence of agglomerated GnPs sheets that behave as $\mu \mathrm{m}$ size fillers with low surface area or as micro-centres of stress concentration ${ }^{[9]}$. For the hybrid nanocomposites, at an overall concentration of $0.043 \mathrm{wt} . \%$, it was found a significant increase in tensile modulus $(16 \%)$ and tensile strength $(1.1 \%)$, relative to the CNTs nanocomposites containing only CNTs. Compared to GnPs nanocomposites, an increase of $23 \%$ relative to the best behaviour achieved with GnPs for the tensile modulus and an increase of $8.6 \%$ for the best behaviour achieved with GnPs in tensile strength was observed. This demonstrates again the synergetic effect between 1D-MWCNTs and 2DGnPs with lower concentration than for the single MWCNT or GnP filled systems. This behaviour is explained by the formation of a 3D-structure that delays or avoids reagglomeration of GnPs. Besides that, the extended tentacles of the CNTs in the 3Dstructure result in an entanglement within the matrix and, consequently, in a better interaction between the fillers and the matrix ${ }^{[15,19,23]}$. Therefore, combination of 1D-CNTs 
and 2D-GnPs could be an interesting concept to achieve superior mechanical performance than single filled systems.

The transversal tensile properties of unmodified and modified CFRP composites were evaluated, and the results are shown in Figure 3.
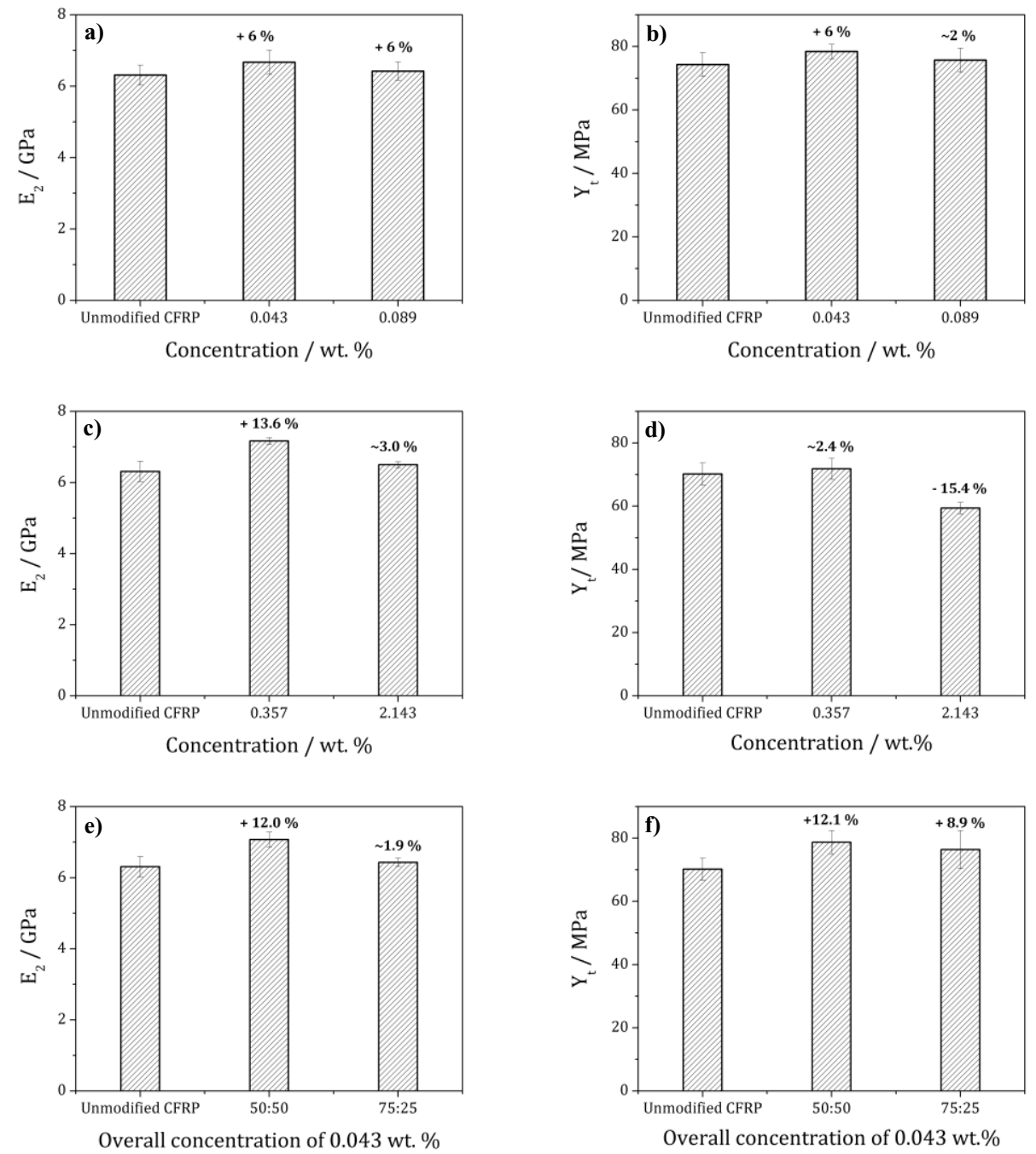

Fig. 3. Transversal tensile properties of modified CFRP composites with CNTs a) - b), GnPs c) - d), and combinations of both (CNTs/GnPs) e) - f), respectively.

In UD-laminates, the mechanical failure at $90^{\circ}$ is initiated within the matrix or at the fibre-matrix interface. Only minor effects were found through the incorporation of 0.043 wt. \% of CNTs ( $6 \%$ ). GnPs do not seem to be effective to enhance the $Y_{t}$ of UDlaminates at $90^{\circ}$ because no appreciable differences with respect to the reference material, i.e. unmodified CFRP, were found. However, in terms of elastic modulus, CFRP composites containing 0.357 wt. \% of GnPs performed the best results $(+13.6 \%)$. Synergetic effects were observed for hybrid CFRP composites in terms of tensile strength, which is enhanced by $\sim 12.0 \%$ when combining CNTs and GnPs. These results are in agreement with trends observed at the nanocomposite level, even with lower improvements 
because of the greater properties achieved in the presence of the fibre, but still with significant improvements that combined with other properties (electrical conductivity) could give a great impact in a variety of applications.

\section{Conclusions}

Combinations of 1D-CNTs and 2D-GnPs used for epoxy-modified suspensions reveal a synergetic effect on the dispersion ability, electrical and mechanical performance. Better dispersion of GnPs was achieved when combined along with CNTs, owing to their ability to form a co-supporting 3D-architecture, which inhibits GnPs re-agglomeration. Synergetic enhancements were found for electrical conductivity and mechanical performance, at an overall concentration of $0.043 \mathrm{wt}$. \%, with lower concentration than single MWCNT or GnP filled systems, owing to the ability of the 3D-architecture to facilitate the electron transport throughout the polymer, and improve the stress transfer between the matrix and the nanoreinforcement. The transversal tensile properties of CFRP composites, also shows synergetic effects for the MWCNTs and GnPs system. Therefore, CNT/GnP hybrid systems could be an appealing approach for multifunctional reinforcements oppositely to single filled systems.

The authors would like to acknowledge funding from project ModComp - Modified cost effective fibre based structures with improved multifunctionality and performance (Project ID: 685844), financed and supported by European Unionand and project PTDC/CTM-POL/4607/2014 "Nano-MFC High performance multifunctional composite materials based on self-assembly approaches" by Fundação para a Ciência e Tecnologia (FCT) cofinanced by Programa Operacional Regional do Norte (NORTE2020), through Fundo Europeu de Desenvolvimento Regional (FEDER).

\section{References}

1. Z. Spitalskya, D. Tasis, K. Papagelis, C. Galiotis, Prog. Polym. Sci. 35 (2010) 357401.

2. R.Sengupta, M. Bhattacharya, S. Bandyopadhyay, A.K. Bhowmick, Prog. Polym. Sci. 36 (2011) 638-670.

3. X. Sun, H. Sun, H. Li, H. Peng, Adv. Mater. 25 (2013) 5153-5176.

4. K. Kalaitzidou, H. Fukushima, L.T. Drzal, Carbon 45 (2007) 1446-1452.

5. S. Kim L.T. Drzal, J Adhes SciTechnol 23 (2009) 1623-1638.

6. R. M. Santos, S. T. Mould, P. Formánek, M. C. Paiva 1, J. A. Covas, Polymers 10 (2018) 222.

7. Steurer, P.; Wissert, R.; Thomann, R.; Mülhaupt, R. Macromol. Rapid Commun. 30 (2009) 316-327.

8. H. Kim, A.A. Abdala, C.W. Macosko, Macromol. 43 (2010) 6515-6530.

9. S.Y. Yang, W.N. Lin, Y.L. Huang, H.W. Tien, J.Y. Wang, C.C.M. Ma, S.M. Li, Y.S. Wang, Carbon 49 (2011) $793-803$.

10. J. Li, P.S. Wong, J.K. Kim, Mater. Sci. Eng. A 483-484 (2008) 660-663.

11. A. Yu, P. Ramesh, X. Sun, E. Bekyarova, M. E. Itkis, R.C. Haddon, Adv. Mater. 20 (2008) 4740-4744.

12. C. Kostagiannakopoulou, G. Maroutsos, G. Sotiriadis, A. Vavouliotis, V. Kostopoulos, Proc. SPIE 8409 (2012), Third International Conference on Smart Materials and Nanotechnology in Engineering, 840911. 
13. H. Fan, N. Zhao, H. Wang, J. Xu, F. Pan, J. Mater. Chem. A, 2 (2014) 12340-12347.

14. K. Zhang, X. Duan, X. Zhu, D. Hu, J. Xu, L. Lu, H. Sun, L. Dong, Synth. Metals 195 (2014) 36-43.

15. L.Yue, G. Pircheraghi, S. A. Monemian, I. M.Zloczower, Carbon 78 (2014) $268-278$.

16. T. Kamae, L.T. Drzal, Compos.Part A 43 (2012) 1569-1577.

17. A. Scuratia, D.L. Fekeb, I. M. Zloczowera, Chem. Eng. Sci. 60 (2005) $6564-6573$.

18. I.D. Rosca, S.V. Hoa, Carbon 47 (2009) 1958 - 1968.

19. W. Li, A. Dichiara, J. Bai, Compos. Sci. Technol. 74 (2013) 221-22.

20. T. Liu, P. Wu, C. Gao, P. Feng, T. Xiao, Y. Deng, C. Shuai, S. Peng, Biomed Res. Int. 2016 (2016).

21. A. Allaouia, S. Baia, H.M. Cheng, J.B. Bai, Compos. Sci. Technol. 62 (2002) 19931998.

22. S. Kumar, L.L. Sun, S. Caceres, B. Li, W. Wood, A. Perugini, R.G. Maguire, W.H. Zhong, Nanotechnology 21 (2010) 105702.

23. S. Chatterjee, F. Nafezarefi, N.H. Tai, L. Schlagenhauf, F.A. Nüesch, B.T.T. Chu, Carbon 50 (2012), 5380-5386. 